\title{
Children's Participation in the Design of Physical Activities Conducted in the Outdoors
}

\author{
Fiona Wood ${ }^{1}$, Fraser Bruce ${ }^{2}$, Seaton Baxter ${ }^{3}$ \\ ${ }^{1}$ Institute of Health and Welfare, Robert Gordon University, Aberdeen, UK \\ ${ }^{2}$ Duncan of Jordanstone College of Art and Design, University of Dundee, Dundee, UK \\ ${ }^{2}$ The Centre for the Study of Natural Design, University of Dundee, Dundee, UK \\ Email: f.k.wood@dundee.ac.uk
}

Received September $17^{\text {th }}, 2012$; revised October $20^{\text {th }}, 2012$; accepted November $4^{\text {th }}, 2012$

\begin{abstract}
Background: Despite recent UK Governmental policy changes concerning the amount of outdoor, physical activity children are currently engaged in (LTS, 2010), there is a gap in the academic literature concerning children's personal preferences for structured play and learning through physical activity in outdoor environments. Aim and objectives: This research explores the context of residential outdoor learning; with a particular focus on the contribution this experience may have on children's preferences for learning and play through healthy physical activity in the outdoors. Methods: Eco-analysis and Personal Construct Psychology experiments (Catherine Ward-Thompson, 1995) were conducted with twenty children (aged eleven to twelve years), participating in a five-day residential stay at an outdoor learning center in order to ascertain their play preferences before and after their stay. Findings: Analysis of the data indicated that children had a preference for outdoor, physical play activity. However, their usual play typically involved only indoor, sedentary activity (e.g. games consoles and television) whilst at home. Evidence suggests that the desired play of children is being ignored in favor of the "plugged in environments" (Louv, 2005) found in the modern family home. Conclusion: This research highlights the importance of implementing outdoor learning policies and practice into the current UK curriculum on a more regular basis for the benefit of young children's health and physical wellbeing. This article concludes with future recommendations for the implementation of new strategies for outdoor learning providers that would support and extend children's physical activity in the outdoors without destroying their enjoyment, exploration or play.
\end{abstract}

Keywords: Structuredplay; Nature; Children; Outdoor Learning; Physical Activity

\section{Introduction}

Our concern in this research and expressed in this paper is to understand the context, from a child's perspective, of learning in the outdoors (in a residential setting) in order to develop better participatory programmes which integrate healthy physical activities with ecological appreciation and learning.

More than ever before, young people are being severely and sometimes unfairly criticised for their aberrant behaviour. This can range from vandalism to random acts of violence and even murder. Much of this is inexcusable but poorly understood. Some of our best intellectual youngsters can succumb to the pressures to compete exerted by family, friends and society as a whole. In this "hothouse" environment (Quart, 2006) many youngsters end up on drugs, prescribed or otherwise, in marauding gangs, or ultimately "go postal" (Ames, 2007), kill and commit suicide.

Many children have been divorced from or deprived of the very skills and experiences now needed to face up to and challenge the many crises in the world, for example, climate change, loss of biodiversity, social inequity and so on. Without these early skills and experiences, the problems are denied or circumvented with diversionary tactics and the world becomes a worse place for their future. Many diversionary tactics find their catalysts in the world of designed artefacts and powerful advertising. From an ecological perspective, however, children are becoming alienated from nature and suffer from what Louv (2006) refers to as "nature-deficit disorder", just at a time when we need to be more connected in order to understand and correct the problems we ourselves have created in an unsustainable world.

In 2004, the Scottish Government developed a new initiative for Scottish education called "A Curriculum for Excellence" (CfE) aimed at preparing children for adult life in the $21 \mathrm{st}$ Century (SEED, 2004). This new educational agenda offered a child-centered approach to encourage children to become: 1) Successful learners; 2) Confident individuals; 3) Responsible citizens; and 4) Effective contributors to society. A review by the UK Minister of Education (2004), confirmed that outdoor learning could play an important role in satisfying the development of children's early learning of these four capacities, whilst also contributing significantly to their involvement in the natural world (LTS, 2007). These political concerns may be the result in part, of recent evidence suggesting that children are now not only less active, but they are less risk aware and demonstrate a decreased interest in the natural world, often favouring, instead, "plugged-in" play environments (Louv, 2005; Gill, 2007, 2010; Honore, 2008).

So, it appears that learning in the outdoors can reconnect children with nature and their local communities whilst providing them with the opportunity to develop the skills necessary to 
recover from an ecologically impoverished society. To an even greater extent, outdoor learning promotes physical activity in all aspects of learning, leading to positive impacts on the participant's health and wellbeing (FPH, 2010). However, whilst children are naturally active in their own play and games (i.e. unstructured play activities), Physical Education (PE) and adult-directed sports in primary and secondary schools do not appear to increase the physical activity levels of children in the same way (Gnanapragasam, 2010). However, participation in sports can lead to improved physical fitness, self-esteem, social capability and team working skills (Hughes, 1999). Nonetheless, it would seem, that outdoor learning can make its contribution to a recovery from these currently unacceptable outcomes and help to restructure a new way forward, especially in the exploration of children's early learning and physical spontaneity.

\section{Research Background}

\section{Children's Learning through Play}

Children's play embraces the educational, recreational and communicational rights of a child (West, 1996). It is a multidimensional concept. It has long been recognized as an important aspect of a child's learning and development (Dansky, 1999), allowing them to express their emotions and deal with everyday situations (James et al., 1998). Petersen (1988) points out that children who have had little opportunity to play can develop serious behavioral problems later in life, such as, learning difficulties and phobias. From a developmental perspective, play can be described as a freely chosen activity required for children to grow into future successful adults (Holloway and Valentine, 2000). Play is a key requirement to the healthy mental, physical, and emotional development of children (Elkind, 2007). Evidence suggests that children learn most effectively through their self-directed play experiences (Power, 2000). So, can we expect children through self-directed play to construct their own practices of healthy physical education?

\section{Children and Adult Directed Play}

Play is well known as a behavior that does not need to be watched, supervised, prearranged or encouraged by adults (Schwartzman, 1983). This is child-directed play and is characterized by activities created by the child that involve minimal equipment and are conducted out with an adult's supervision (Adler \& Adler, 1998).

Child directed play is "self-initiated" and is free from the externally imposed rules or constraints common in adult-directed activities (Dansky, 1999). From a developmental perspective, child directed activities teach children a variety of essential life skills: communication, resilience, self-reliance, compassion, negotiation, resourcefulness and so on (Adler \& Adler, 1998). In addition, Asthana and Revill (2008) would also add developing friendships, risk awareness and confidence to this list.

A common feature of play in outdoor environments is the use of games. Indeed, children often develop and engage in games through choice as well as when instructed to do so. All over the world, children play and create games as one of their most popular physical activities (Piaget, 1962). It is through these self-directed-games that children gain the opportunities for important informal and social learning (Lever, 1978). There are many reasons why children might engage in self-directed games. For example, sometimes they are played for enjoyment, pleasure and refuge or for social acceptance, whilst at other times they are just for passing the time. Furthermore, childdirected-games, or games-with-rules, provide a multitude of cognitive skills necessary in later adult life (Hughes, 1999). These may include, for example, the development of moral values (Piaget, 1962), group or teamwork skills (Lever, 1978), informal learning environments important to children's development (Roussou, 2004), or strategic thinking through the structuring of rules (Lever, 1978).

However, not all play leads to games because, according to Gazzard (2007), it is the inclusion of rules that govern the player's behavior that creates a game. This, in turn, creates play boundaries. These boundaries may be defined by children, or by adults and in the latter case the games often become competitive, organized sports (Lever, 1978). For the former, however, this creates child-directed games-with-rules.

Adult involvement in children's play is often considered to have a detrimental effect on child directed play (Opie \& Opie, 1969). Adult-directed play changes the form and frequency of child-directed play, often causing it to cease entirely (Schwartzman, 1983).

This is not to say that adult directed play has no place in the life of a child. Adult-directed play is usually supervised by adults and encompasses all games and play activities introduced to children by adults, such as team sports and structured games (Schwartzman, 1983). For this purpose, adults may take on a number of roles including supervisor, tutor, instructor, coach and so on. Unlike child-directed play that can occur anywhere and at anytime, adult-directed play is usually structured in time and location (Schwartzman, 1983).

Adult-directed play, however, is now more prevalent than ever before (Power, 2000). In addition, modern society has also witnessed another shift in direction, as parents become too busy to supervise and direct their children's play at all times (Karsten \& Vliet, 2006). Caught in a dilemma between being unable to supervise their children and not wanting their children to play unsupervised, there appears, for parents, to be only one solution: indoor supervised play (Honoré, 2008). This shift towards indoor play where children can be supervised, but don't need to be constantly engaged with, is reinforced by arguments about increased traffic flow and predatory adults (Mayo \& Nairn, 2009) and becomes a shift in parenting styles to a managerial approach. Honore (2008) calls this "The Age of the Managed Child".

However, structured adult-directed play is also found in residential outdoor learning settings (LTS, 2010). Here, adultdirected play allows children to develop understandings and abilities in co-operation, practice and order, all of which are valuable skills in developing them as well rounded citizens. Furthermore, outdoor learning environments, in particular those which focus on child-centered learning approaches (e.g. forest schools) increase the opportunities for children to learn and take appropriate risk within a safe and familiar environment (O’Brien \& Murray, 2007).

Evidence suggests that supporting children to conduct their own play and learning in the outdoors promotes recreational activity in childhood that extends into adult life (Gnanapragasam, 2010). This should lead to improved health and wellbeing, whilst allowing children to also engage with nature at their own pace. Sobel (1993) suggests that this will allow children to create a connection and ownership with the natural environment. A possible outlet for these outdoor, child-directed play and 
games may be found in residential outdoor learning environments where children are given the time and freedom to conduct their own play and learning.

It is clear that the best environments for childhood learning are those which balance, in yin-yang fashion, different types of play, individual and group activities, different environments with different resources for learning, etc. and where children are encouraged to seek their own learning as well as being reassured by enthusiastic and empathetic tutors.

\section{Research Aim}

The main of this research study was tounderstand the context, from a child's perspective, of learning in the outdoors (in a residential setting) with a particular focus on the contribution this experience may have on a child's preference for learning and play through healthy physical activity in the outdoors.

\section{Research Approach and Methodology}

\section{Methodology}

This study was concerned with using a research method that would uncover participating children's preferences for physical play activity in the outdoors. Furthermore, the method should provide an opportunity to establish the effects, if any, of a short residential stay in outdoor learning in a before and after study. Giving children the opportunity to discuss their responses was an additional desirable aspect of the chosen method. Finally, it was considered essential that the chosen method should provide the opportunity for the development of design recommendations that had been informed by participating children.

Considering these constraints, Personal Construct Psychology (PCP), a method developed by Kelly (1955) and later refined by Aspinall and Ujam (1992) and Ward-Thompson (1995), was chosen.

Kelly (1955) believed that human behavior was based on "individual constructions of reality rather than direct contact with reality". Kelly's principle of PCP is therefore based on the concept that the human perception and response to reality is mediated by these constructions (Ward-Thompson, 1995). The properties of these constructions are elements (objects, events, places, and people) and constructs (the distinguishing aspects of the individual aspects, features or qualities).

PCP has been used to elicit design outputs in architectural design since the early 1970s. Indeed, several designers have noted its potential and Peled (1976) in particular, used it to explore aspects of place (Aspinall \& Ujam, 1992). Since its introduction to this field of design, PCP has been used, on occasion, with children acting as active participants in the final stages of the design process (Aspinall \& Ujam, 1992; WardThompson, 1995). This suggested that PCP might provide suitable data for analysis and assist in the re-design of outdoor programmes and activities for implementation in residential outdoor learning. PCP could then be applied in conjunction with the closely related method of Ecoanalysis (Peled, 1990). Eco-analysis is aimed at exposing participants underlying emotional responses to the elements they place on a spatial diagram (Ward-Thompson, 1995). Peled developed this method in order to understand human experiences of place in terms of design and psychotherapy (Aspinall \& Ujam, 1992).

Ecoanalysis is based on the notion that we experience the space around us in the same way that we experience our own bodies (Aspinall \& Ujam, 1992; Ward-Thompson, 1995). It is a location task which explores the spatial organization in which participants experience the front, back, left, right and central aspects of a spatial layout (Figure 1) within which they are asked to place elements. These specific "locations" relate to the space around our bodies.

Aspinall and Ujam (1992) claim that an "expressive analogue" is created in the analysis of the participant's arrangements. This portrays the importance and emotions embodied in the participant's spatial ordering. For instance, Peled's assumptions are that when a child is asked a question and responds by placing a counter on the spatial diagram its location has the following meaning: 1) In the center implies a wish for integration; 2) In the front implies the participant would openly state a desire for this element; 3) In the back implies the participant may not so openly admit a desired integration of this element; 4) In the left implies rejection; and 5) In the right implies acceptance (Aspinall \& Ujam, 1992). This method would allow participating children to be involved in the future design of activities.

To carry out a study using these Projective Methods involves three stages. Stage One is used to explore the participant's holistic experience of the site. PCP is used "to draw out aspects of place experience, activities and artifacts with which the respondents identified in a positive way" (Ward-Thompson, 1995: p. 126). In this way, participants identify their favored characteristics within the site using a selection of photographs (Figure 2). The use of photographs during PCP sessions with children has proven successful in previous applications of these projective methods (Aspinall \& Ujam, 1992; Ward-Thompson, 1995).

In Stage Two these aspects are listed as elements and transferred onto small white counters. Finally, in Stage Three the participants are involved in an Eco-analysis session where they place these counters on to a spatial diagram (Figure 1).

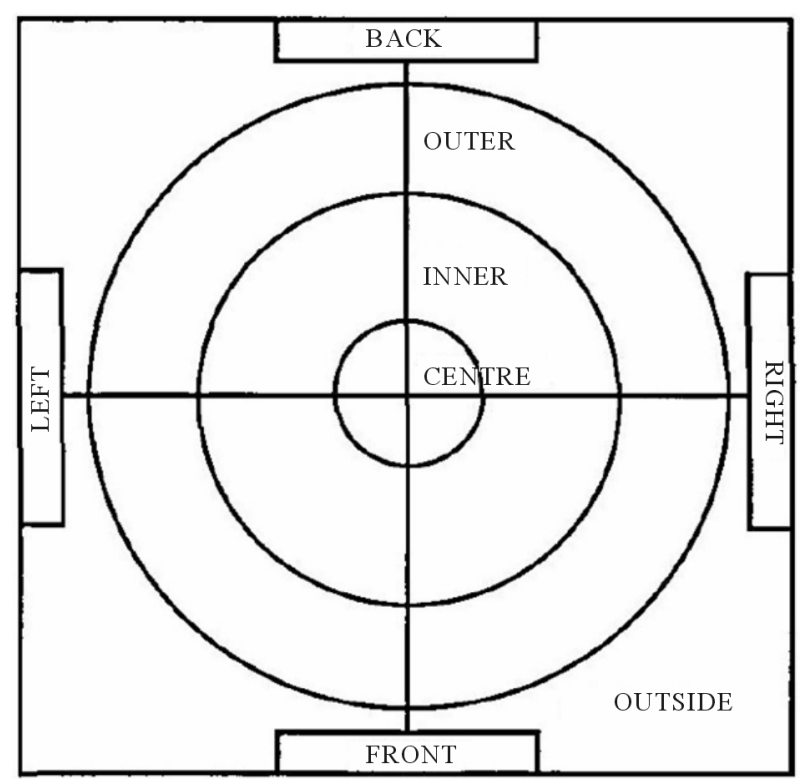

Figure 1.

Example of Eco-analysis spatial layout diagram used for the positioning of element counters. Source: Ward-Thompson, C. (1995) School playground design: a projective approach with pupils and staff. Landscape Research, 20, 124-140. 


\section{Participants}

The study was conducted with a group of 20 children aged between 11 and 12 years (ten females and ten males) participating in a five-day (Monday to Friday inclusive) residential stay in an outdoor learning centre in Scotland.

\section{Research Procedure}

PCP was limited to 15 minutes with each child on Day One (Monday) and Day Four (Thursday) of their residential stay in outdoor learning. During this time, the first 10 minutes were spent conducting a PCP session whilst the remaining 5 minutes were spent interviewing each child about their play preferences. An additional period of 30 minutes was also allocated for the Eco-analysis session on Day Three (Wednesday).

Details of the protocols for the various stages are now described.

Stage One-Image Selection (PCP): Each child was presented with a series of twenty A4 color photographs (Figure 2). Then each child was asked to imagine they were with their best friend and to answer the following five questions: 1) What is your ideal outdoor play environment? Select a photograph that best shows this; 2) Which three things do you like most about the photograph you have chosen? 3) What do you not like about the photograph you have chosen? 4) What would you do there? and 5) Think of your ideal place of play. How does it differ from the photograph you have chosen?

Children's responses to each of these questions were recorded for later analysis.

Stage Two-Element Identification and Categorization: This stage was conducted by one of the authors (FW) without the involvement of the participants. The responses given during the first stage generated a number of elements and constructs associated with outdoor play and learning environments. During this stage, the results from each participating child were listed and grouped into three categories: 1) Aspects of place experience e.g. clean, quiet, shaded and so on; 2) Activities e.g. climbing, running, talking, sitting and so on; and 3) Artifacts e.g. trees, bushes, dens, seats, buildings and so on.

These elements were then subsequently written onto white

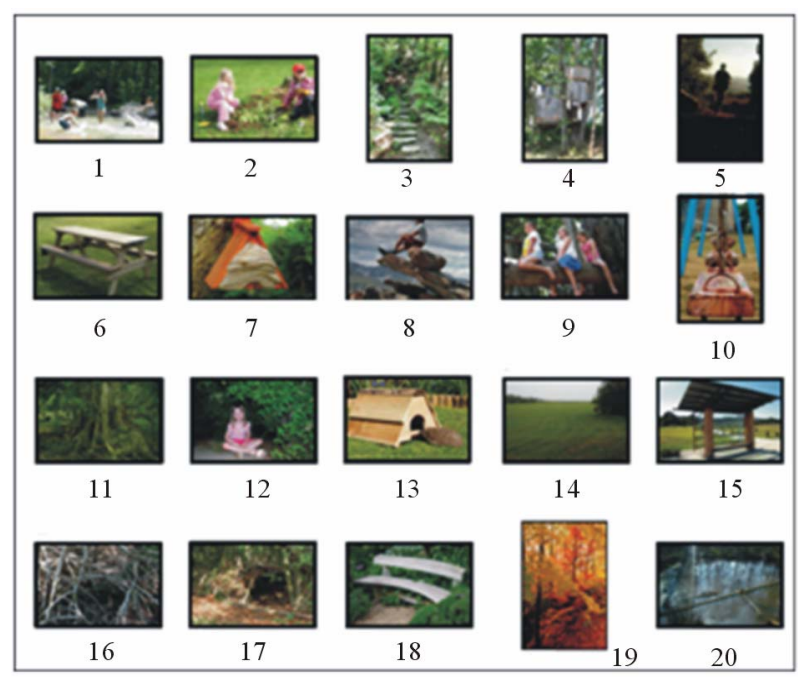

Figure 2.

Photographs shown to participants during Stage One. counters for use during Stage Three (Eco-analysis). Duplicate counters were made for each of the elements so that the children could place them within the spatial layout more than once.

Stage Three-Eco-Analysis: During this stage only 12 of the original 20 participating children were available. These 12 children were divided into three small groups of four children.

Each group were given 20 minutes to converse and arrange the element counters onto the spatial diagram in regards to their ideal outdoor play and learning environments. Three identical sets of element counters had been created for this purpose- one for each of the participating groups.

The final layouts of each group were noted. These layouts were later replicated, using an electronic drawing software package, for subsequent analysis.

Stage Four-Play Images: In Stage Four additional time was spent with each child at the start and end of their residential stay in order to ascertain their play preferences. During these sessions, each participating child was presented with a series of twenty A4 color photographs representing various scenes of play (Figure 3).

On Day 1, these images were laid out in front of each child and they were then asked to: 1) Think of your usual play activity. Select a photograph which best shows this; 2) Think of your ideal play activity. Select a photograph that best shows this.

On Day 4, the same images were laid out in front of each child, however this time only Question 2 was asked.

Children's responses to each of these questions were recorded verbatim.

\section{Limitations of the Study}

The small number of participants who were available to be involved in the study and had the necessary ethical consent, reduced the amount of statistical analysis that could be performed.

The outdoor centre in which the study was being conducted determined the timing of events and the availability of participants. No pilot study was conducted to test the research approach. As such, the same form of analysis used by Aspinall and

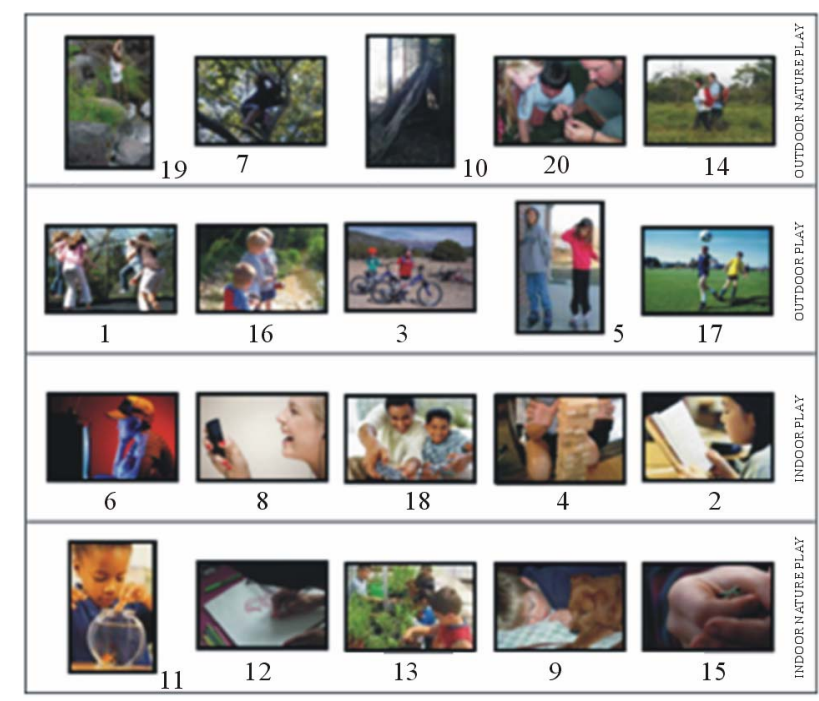

Figure 3.

Photographs shown to participants during Stage Four. 
Ujam (1992) and Ward-Thompson (1995) was applied and followed accordingly.

Furthermore, an application of a method that uses images adds another level of ambiguity to the interpretation of the data. Therefore, had a pilot study been conducted, this may have improved the selection of photographs for the main study.

The placing of elements on the spatial layout furthered the ambiguity of the data gathered. Indeed, it was unclear if the children were following the method of mapping out their ideal outdoor play environment or, alternatively, if they were just trying to fill all areas of the diagram.

Generating a list of elements from children's verbal responses also proved difficult. Their vocal responses varied from grunts to babble and their vocabulary was limited. Furthermore, differentiating between elements of artifacts, activities and experience of place proved difficult when, of course, these are all interwoven and connected. Artifacts, for example, tend to define the activities that occur in spaces, thus making them into places.

\section{Data Analysis and Results}

Stage One-Image Selection (PCP): Responses to Q1 (see p. 4) were analyzed in relation to the most popular (top 70\%), marginally popular (next $30 \%$ ) and least popular $(0 \%)$.

Figure 4 shows the rank order of the total selection of these photographs by boys and girls.

Stage Two-Element Identification: Responses to Questions 2-5 (see p. 4) were analysed, by taking only the responses given by the fourteen children who chose the four most popular photographs in response to Question 1.

Although an identical interview procedure was followed for each child, it should be noted that, in some cases, when responding to Question 2, children indicated more than three things, only two things, or sometimes nothing at all. However, all elements discussed were listed even in cases where a child mentioned the same element more than once.

The process identified 25 elements liked and 5 elements disliked, in addition to 12 elements of ideal places to play, in response to these questions.

Stage Two-Element Categorization: The elements gathered from the participant responses to Q2 and Q4 were categorized according to one of three categories: 1) an Experience of Place; 2) an Activity or; 3) an Artifact (Table 1).

Table 2 indicates that Activities were the most frequently chosen category, followed by Experience of Place, and then, finally, Artifacts. It also shows that Photograph no. 1 (splashing) had the most responses across all categories whilst Photograph no. 8 (rock climbing) had the least. Photograph no. 8 was also the only photograph that did not contribute to any Artifact category, but was the highest contributor to the Activity category.

Stage Three-Eco-Analysis: This section illustrates the children's placement of the categorized elements (identified in Stage Two) onto an Eco-analysis diagram.

Figure 5 shows the aggregate data from all three groups of children involved in this process.

The three element categories (activity, artifact and experience of place) are distinguished through the use of different colors: 1) Activity-Blue; 2) Place-Orange; and 3) Artifact-Pink.

This shows that Artifact elements were by far the most

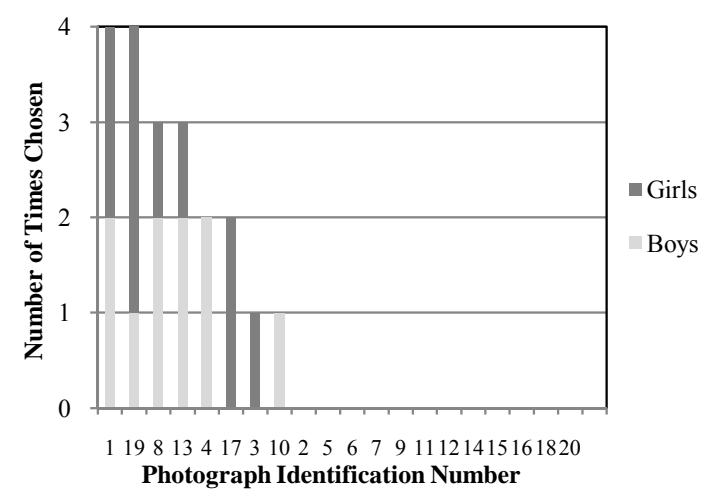

Figure 4.

Rank order of selections of all photograph choices in response to Question $1(\mathrm{n}=20)$.

Table 1.

Categorisation of elements identified in response to Questions 2 and 4 with regard to the four most popular photographs $n=14$.

\begin{tabular}{cccc}
\hline Element & Category & Element & Category \\
Colour & Place & Walk & Activity \\
Nice Views & Place & Look(ing) & Activity \\
Fun & Place & Paddling & Activity \\
Nice & Place & Sit & Activity \\
Nice Scenery & Place & Shout & Activity \\
Cute & Place & Splash & Activity \\
High/Height & Place & Play & Activity \\
Steep & Place & Water & Artefact \\
Sunny & Place & Animals Homes & Artefact \\
Adventure & Place & Rocks & Artefact \\
Peaceful & Place & Garden & Artefact \\
Nice Place & Place & Forest & Artefact \\
Touch Animal & Activity & Leaves & Artefact \\
Picnic & Activity & Bike & Artefact \\
(Make a) Den & Activity & Animals & Artefact \\
\hline
\end{tabular}

popular choice for location on the spatial diagram. In addition, this also shows that all three of the element categories were distributed across the entire spatial layout.

Stage Four-Play Images: Responses to Q1 (see p. 4) were analyzed according to the rank order of the total selection of photographs by boys and girls (Figure 6).

Responses to Q2 "Think of your ideal play activity. Select a photograph which best shows this" were analyzed according to the total number of times each photograph was chosen for each gender, before and after their residential stay (Figure 7 and Tables 3 and 4). To establish whether there was a significant gender associated difference in choice of indoor or outdoor play at the start and end of their residential period, differences for the paired data were then calculated and a sign test conducted. 


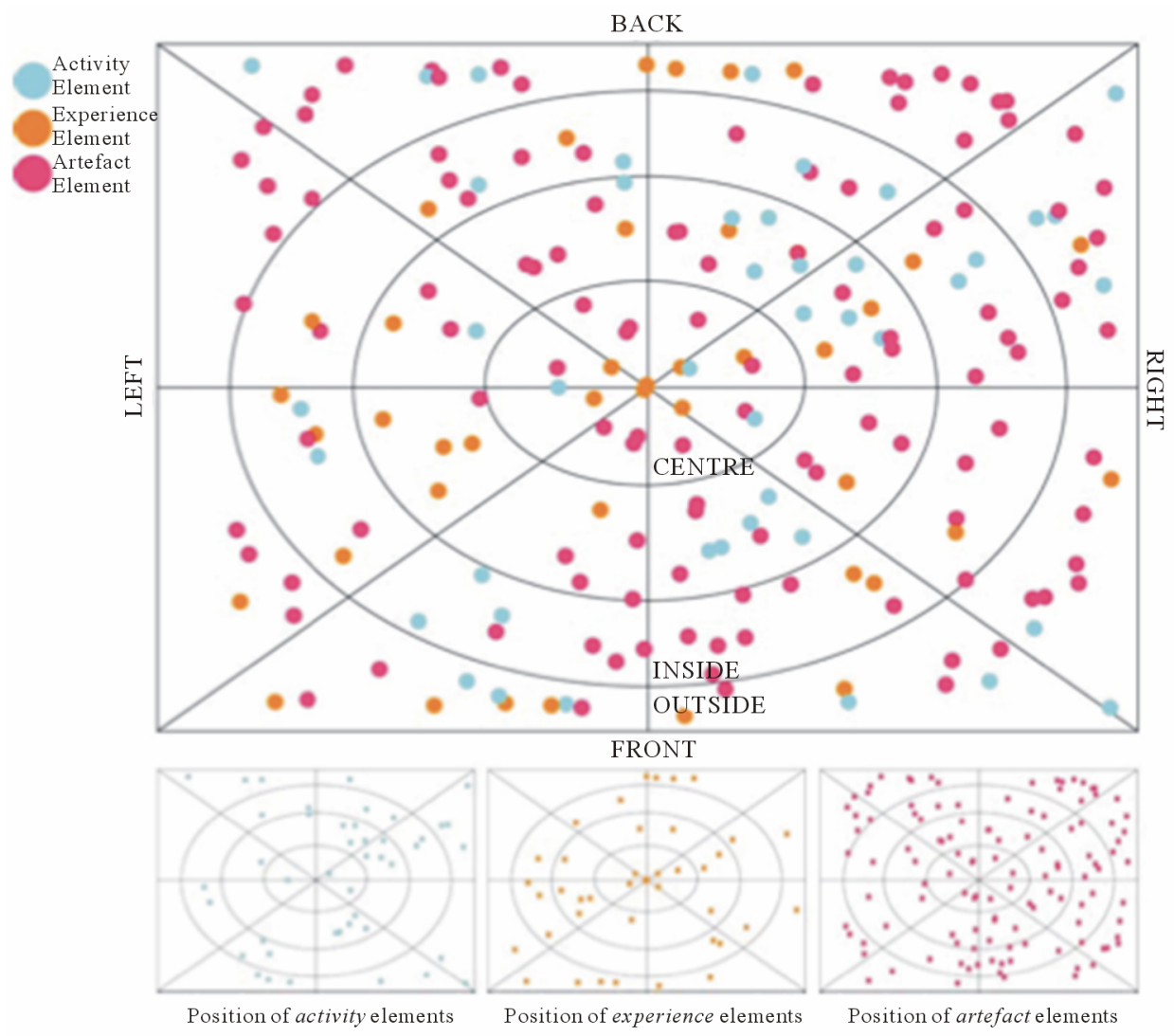

Figure 5.

Participant's element placement during Stage Two (for total number of respondents $n=12$ ).

Table 2.

Categorisation of all elements identified as being liked about the four most popular photographs during Questions 2 and 4 with regard to individual photograph choice $(\mathrm{n}=14)$.

\begin{tabular}{|c|c|c|c|c|}
\hline Categories & Place & Activities & Artifacts & $\begin{array}{l}\text { Total Times } \\
\text { Mentioned }\end{array}$ \\
\hline \multicolumn{5}{|l|}{ Photo 1 (4) } \\
\hline & 6 & 9 & 5 & 20 \\
\hline \multicolumn{5}{|l|}{ Photo 19 (4) } \\
\hline & 7 & 6 & 1 & 14 \\
\hline \multicolumn{5}{|l|}{ Photo 8 (3) } \\
\hline & 2 & 11 & 0 & 13 \\
\hline noto & & & & \\
\hline & 7 & 5 & 2 & 14 \\
\hline $\begin{array}{l}\text { Total Times } \\
\text { Mentioned }\end{array}$ & 22 & 31 & 8 & 61 \\
\hline
\end{tabular}

Tables 3 and $\mathbf{4}$ show that both genders demonstrated a preference for outdoor play at the start of their residential stay in outdoor learning. However, due to the subjective nature of a research method using images, no assumptions could be made about the symmetry or normality of the data, so a nonparametric sign test was conducted on these results to determine if observed differences could be attributed to the residential stay. The further away from 0 the mean difference was, the more likely it was that the play preferences had changed after children had experienced a residential stay.

The null hypothesis was that no difference between the samples would be observed $(\mathrm{m} 0=0)$. Any differences equal to $\mathrm{m} 0$ were removed from the sample and the number of positive results was counted. This number is the test statistic and its null distribution is $\mathrm{B}(\mathrm{n}, 1 / 2)$ where $\mathrm{n}$ is the sample size (after removing any values equal to $\mathrm{m} 0$ ). This test was conducted using Minitab software (Table 5).

Table 5 shows there is little evidence to refute the null hypothesis for boys, but some evidence to challenge the null hypothesis for girls. However, the data suggests that neither gender demonstrated a significant difference in their change of play preferences towards outdoor play after their residential stay in outdoor learning.

\section{Discussion}

\section{PCP and Eco-Analysis-Discussion of Methods}

The use of PCP and Eco-analysis in the context of this study 


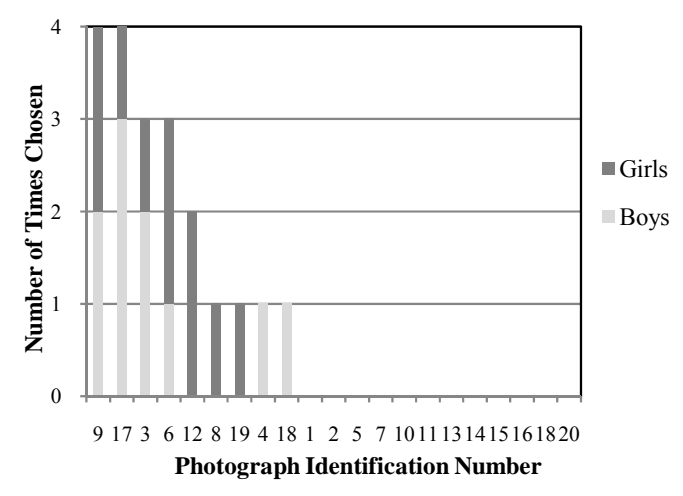

Figure 6.

Rank order of selections of all photograph choices in response to Question $1(\mathrm{n}=20)$.

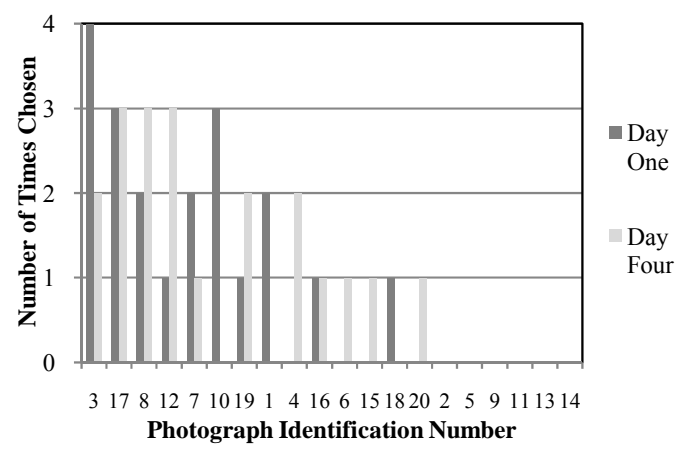

Figure 7.

Response rates of all photograph choices in response to Question 2 on Days 1 and $4(n=20)$.

Table 3.

Response rate of indoor play photograph choices before and after, girls and boys $(\mathrm{n}=20)$.

\begin{tabular}{ccccccc}
\hline & $\begin{array}{c}\text { Girls "Indoor Play" } \\
\text { Photograph Choices in } \\
\text { Response to Q2 }\end{array}$ & \multicolumn{2}{c}{$\begin{array}{c}\text { Boys "Indoor Play" } \\
\text { Photograph Choices in } \\
\text { Response to Q2 }\end{array}$} \\
\cline { 2 - 6 } & Day 1 & Day 4 & $\begin{array}{c}\text { Day 1 - } \\
\text { Day 4 }\end{array}$ & Day 1 & Day 4 & $\begin{array}{c}\text { Day 1 - } \\
\text { Day 4 }\end{array}$ \\
\hline Photo 2 & 0 & 0 & 0 & 0 & 0 & 0 \\
Photo 4 & 0 & 0 & 0 & 0 & 2 & -2 \\
Photo 6 & 0 & 0 & 0 & 0 & 1 & -1 \\
Photo 8 & 1 & 3 & -2 & 1 & 0 & 1 \\
Photo 9 & 0 & 0 & 0 & 0 & 0 & 0 \\
Photo 11 & 0 & 0 & 0 & 0 & 0 & 0 \\
Photo 12 & 1 & 3 & -2 & 0 & 0 & 0 \\
Photo 13 & 0 & 0 & 0 & 0 & 0 & 0 \\
Photo 15 & 0 & 1 & -1 & 0 & 0 & 0 \\
Photo 18 & 0 & 0 & 0 & 1 & 0 & 1 \\
Sum & 2 & 7 & -5 & 2 & 3 & -1 \\
Mean & & & -0.5 & & -0.1 \\
\hline
\end{tabular}

Table 4.

Response rate of outdoor play photograph choices before and after, girls and boys $(\mathrm{n}=20)$.

\begin{tabular}{ccccccc}
\hline & \multicolumn{2}{c}{$\begin{array}{c}\text { Girls "Outdoor Play" } \\
\text { Photograph Choices in } \\
\text { Response to Q2 }\end{array}$} & \multicolumn{3}{c}{$\begin{array}{c}\text { Boys "Outdoor Play" } \\
\text { Photograph Choices in } \\
\text { Response to Q2 }\end{array}$} \\
\hline & Day 1 & $\begin{array}{c}\text { Day } \\
4\end{array}$ & $\begin{array}{c}\text { Day 1 - } \\
\text { Day 4 }\end{array}$ & Day 1 & $\begin{array}{c}\text { Day } \\
4\end{array}$ & $\begin{array}{c}\text { Day 1 - } \\
\text { Day 4 }\end{array}$ \\
\hline Photo 1 & 2 & 0 & 2 & 0 & 0 & 0 \\
Photo 3 & 1 & 0 & 1 & 3 & 2 & 1 \\
Photo 5 & 0 & 0 & 0 & 0 & 0 & 0 \\
Photo 7 & 2 & 1 & 1 & 0 & 0 & 0 \\
Photo 10 & 1 & 0 & 1 & 2 & 0 & -2 \\
Photo 14 & 0 & 0 & 0 & 0 & 0 & 0 \\
Photo 16 & 1 & 0 & 1 & 0 & 1 & -1 \\
Photo 17 & 0 & 0 & 0 & 3 & 3 & 0 \\
Photo 19 & 1 & 2 & -1 & 0 & 0 & 0 \\
Photo 20 & 0 & 0 & 0 & 0 & 1 & -1 \\
Sum & 8 & 3 & 5 & 8 & 7 & 1 \\
Mean & & & 0.5 & & & 0.1 \\
\hline
\end{tabular}

Table 5.

Results of a nonparametric sign test on the data for girls and boys in response to Question 2.

\begin{tabular}{ccccccc}
\hline & $\mathrm{N}$ & Below & Equal & Above & $\mathrm{P}$ & Median \\
\hline $\begin{array}{c}\text { Difference } \\
\text { Indoor Girls }\end{array}$ & 10 & 3 & 7 & 0 & 0.2500 & 0.000 \\
$\begin{array}{c}\text { Difference } \\
\text { Outdoor Girls } \\
\begin{array}{c}\text { Difference Indoor } \\
\text { Boys }\end{array}\end{array}$ & 10 & 1 & 4 & 5 & 0.2188 & 0.500 \\
$\begin{array}{c}\text { Difference } \\
\text { Outdoor Boys }\end{array}$ & 10 & 3 & 6 & 1 & 0.6250 & 0.000 \\
\hline
\end{tabular}

proved to be useful in considering the redesign of programmes and activities for children's outdoor play and learning. Firstly, these techniques are designed to help participants to identify their desires by tapping into their subconscious responses. Eiser (1986) refers to these as "pre-conscious" factors. These are especially important when designing with and for children who may have different and opposing views to those of adults. So, these methods allowed participating children's unconscious preference for different activities and artifacts within an outdoor learning environment to be uncovered. Secondly, the projective methods used during this study had been applied previously as a means for involving children in the design process of both playgrounds (Ward-Thompson, 1995) and landscape architecture (Aspinall \& Ujam, 1992). Thus, little adaptation was required for application in this study. Finally, these projective methods allowed participating children to act as key stakeholders in the design phase of this study.

\section{Eco-Analysis and PCP-Discussion of Findings}

The analyses of participant's location of elements revealed some interesting results. The children demonstrated a desire to 
integrate all 3 categories of the elements presented to them. In particular, artifacts seemed to attract greater interest than activities. Indeed, in terms of total numbers, artifact elements were placed more frequently on the spatial layouts than activity or place elements. However, artifact elements were also placed more often in the outer parts of the spatial layout than in the inner. This suggests that, despite being the most frequently located elements, they may not have been as important as some of the other elements. Indeed, activity elements (building a den, splashing, shouting, playing, exploring, laughing, touching animals, look, sitting and picnicking) were placed in the centre spaces more frequently than the artifact elements (trees, animals, nature, garden, rocks, wood, animals home, friends, water, leaves and bike).

However, each of the artifact elements placed in the centre spaces of the spatial layout (laugh, shout, build dens and touch animals) all raised possibilities for an activity.

Indeed, it would seem that artifacts and activities are interrelated and difficult to separate, especially in the eyes of a child. Therefore, aspects of activity, in addition to artifacts that present possibilities for activity (e.g. rocks to climb), may attract greater interest from children than artifacts that do not seem to offer the same potential for activities. This will be of importance when making recommendations for outdoor learning environments.

Interestingly when placing experience elements in the centre of the spatial layout, the children demonstrated a high preference for the place's sense of peace, color, height, views and just a nice place. This suggests that, despite parental beliefs regarding the boisterous nature of young children, they also appear to desire places for reflection and quiet, much in the same way that adults do. The choice of such places, in particular, in an outdoor learning environment, would add support to the notion of experiential learning and the need to allow children the appropriate spaces in which to reflect on their learning experiences (Beard \& Wilson, 2006).

A closer look at the elements placed on the spatial layouts highlights that trees were also extremely popular with this cohort of children. This may be for two reasons. First, children, especially after spending time in residential outdoor learning, may view trees as "fun" things to climb; after all they have just participated in a "Tree Climb" activity during their residential stay. Second, however, it may be that these children are responding to a tendency towards an association with trees (biophilia). Indeed, other examples of children's tendencies towards nature were also found; with the most frequently positioned elements by all three groups being leaves, trees and animals. These children appeared to demonstrate a desire for the opportunity to engage with nature.

Elements relating specifically to shelter also seemed to be of particular importance. For instance, trees, building a den, sitting and picnicking were all popular central elements. This may be because these children (aged 7 - 12 years) were at a stage in their childhood where their desire for creating small worlds for themselves, out with the confines of their family home, is developing (Sobel, 1996).

It is interesting to also note that the children' dislikes appeared to be predominantly safety orientated, ranging from worries about deep or shallow water and its temperature, to the height of artifacts within their play spaces. Gill (2007) highlights this child-oriented risk-aversion as a rising problem in modern society, resulting from too much adult supervision and adult-directed play.

\section{Play Preferences-Discussion of Findings}

In response to the question about their usual play activity, participating children selected a wide range of photographs. Of the 9 examples of usual play activity selected, the most popular choices was playing with a family pet and playing football. Whilst the former was chosen by boys and girls equally, the latter was chosen predominantly by boys. It is interesting, although perhaps not surprising, that playing with a family pet would be such a popular choice. Indeed, with children having increasingly less opportunities to play outside, unsupervised with friends, parents working increasingly long hours and one child families becoming more common, pets have, unsurprisingly, become the play partner of many modern children.

Playing football, or indeed any sport, was also not a surprising popular choice for the usual play of participating children. Neither was it surprising that this activity was also chosen more frequently by boys than by girls (Hughes, 1999).

Riding a bike and watching television were also equally rated. This time girls demonstrated a preference for watching television, and boys for riding a bike. This is also in line with evidence in the literature which states that girls are more likely to engage in sedentary activities (Lever, 1978), whilst boys will engage in more robust or active play (Power, 2000).

Only a further four activities were chosen by children as representing their usual play. Each of these activities was chosen by only one child: listening to music and playing in rivers were chosen by girls and playing board games and playing the Xbox were chosen by boys.

A further eleven activities were not chosen by any children as examples of their usual play. These were: rollerblading, building dens, playing with fish, trampolining, reading, climbing trees, indoor gardening, walking, playing with frogs, fishing and looking at insects. It is disappointing that so many of these unselected activities were those that would usually occur in the outdoors. Indeed, only one example of outdoor natural play had been chosen (playing in rivers) and by only one child, who, contrary to evidence in the literature, had been female. With only seven children selecting activities that were even remotely physically active, the results suggest that the remaining participating children find passive play adequate in terms of general satisfaction but hardly enough in terms of healthy, physical activity.

Whilst these results support the evidence in the literature, and appear to confirm that children's play is, in fact, moving inside in favor of often electronic activities, it is both unsettling and surprising that this appeared to be what children wanted. Further information from this cohort was now needed to establish whether the play activities described were the choice of the children, or whether other contributing factors influenced their usual play. This was established by asking the same children about their ideal play.

By far the most favored ideal play activity was riding a bike and was chosen predominantly by boys. Building dens and playing football were also highly favored and again chosen predominantly by boys. This is not surprising considering, if given the opportunity, boys often favor energetic, physical activity in outdoor environments. The two most popular activities described by girls were trampolining and climbing trees. Whilst trampolining, occurring in family gardens, was not a surprising 
choice for girls, climbing trees is a much more robust activity and would have been expected, based on the evidence in the literature, to have been more desirable by boys.

\section{Conclusion}

Despite the intriguing possibility and idealistic, almost romantic proposal that all children's learning could occur outdoors the reality is that indoor and outdoor learning must act together (cooperate) in a complimentary fashion and are not substitutes for one another (LTS, 2010).

Learning itself is a deep and pleasurable urge which promotes in young people a feeling of fulfillment and great happiness when engaged in challenging, non-trivial pursuits (Haidt, 2006). For children, play is a prerequisite to enjoyable selflearning and creative problem solving. Furthermore, self-learning conducted in the outdoors is more "real" than the controlled environment of the indoor classroom. It presents the child with more opportunities for choice (because of greater novelty) and more self-discovered challenges (because of greater complexity) in which the learner needs to take responsibility for their own learning and to face the consequences of their own decision making.

Children want to be happy and their parents want them to be happy too. As Guy Claxton says (2008) "they (parents) want them (their children) to be safe, healthy independent people who feel at home in the world; (author's emphasis) who can make and keep friends; who can face what life throws at them intelligently and cheerfully. Most parents are less worried about what form their children's lives take than about their mental and emotional wellbeing. They know that happiness has to do with purpose and passion rather than positivity: with the satisfaction of taking on real challenges and not running away from difficulty" (p. 14). Play is the ideal tool for children's learning.

As discussed previously, children's play can be broken down into two clear domains; Adult-Directed and Child-Directed. Within each of these domains children may engage in indoor or outdoor play. A unique attribute of Child-Directed Play is fantasy or imaginative play, in which children create their own scenarios and environments. Games are also a common feature of play. In child directed games, children learn how to make rules, through which they learn the art of negotiation. In adult directed games, children learn how to obey rules, and the notion of competition is introduced. In these settings, games can quickly change to sports. This occurs when children feel increasingly less responsible for the type of play in which they are engaged, and instead become a participant in a "training" activity. In this sense, all Adult-Directed Play can become training. That is, as soon as a child stops enjoying the activity it changes from a "play" activity to a "learning" activity. This is because, whilst play is an effective learning tool, enjoyment remains a clear requirement of play and so, as soon as an activity ceases to be enjoyed by a child it can no longer be termed Adult-Directed Play, becoming instead Adult-Directed Training.

The role of child-directed or free-play is encouraged in the literature, especially when it occurs in out-of-doors environments. Outdoor, natural environments are particularly ideal as are able to satisfy the creative needs of a child (Maudsley, 2007). Garvey (1977) also confirms that participation in play allows children to develop enhanced motor skills, respond to different levels of aggression and learn how to interact and cooperate with others.

However, whether this learning will have a long-term effect on these children remains unclear. Indeed, whilst Hattie et al. (1997) and Sobel (1996) both conclude that residential outdoor programmes can have a long lasting effect on the lives and future environmental commitment of participants, Mittelstaedt, et al. (1999) suggest a residential experience in outdoor education will only reinforce a pre-existing appreciation for the natural environment. This study suggests that if you are looking for a change in the children's attitudes, as reflected in their choice of indoor/outdoor play, for example, five days in residential outdoor learning environments has little or no effect. But, if a major benefit to many of the children is to get away from school and the continuous overview of their parents, to be with other children (peers) and to have an exciting time, then the effect is significant. The lasting effect of even that is immeasurable. How many people who 50 years ago experienced a stay in residential outdoor learning can clearly identify the benefits they got from the experience? To understand these issues better would require either a large retrospective survey or a longitudinal study.

In parallel to this research two of the authors (SB and FW) conducted a small review of historical children's games, many of which held the desired characteristics of child-directed physical activities conducted in outdoor settings. In particular, the game "Sappy Soddgers" was reviewed. According to Opie \& Opie (1969) this game is classified as a chasing game, collectively described as "three lives".

The aim of the game was to end up with one child as the victor. The game could start with 6 to 16 or more players. The game began with all the players standing in a circle, legs apart and feet touching those of the adjacent players. A ball was thrown in the air in the centre of the circle and the first "thrower" was identified by whose legs the ball went through in coming to a halt. When the thrower was identified everyone else scattered as quickly as possible. Thereafter the ball was always "in play" being thrown by a "thrower" with the intention of hitting another player on the clothed part of the body. A player hit three times was deemed "dead" and given one last free throw which, if successful in hitting another player, led to the resurrection of the original "victim". There was no referee or umpire and any disputes, beyond these pre-defined rules, were resolved by the players. Such resolutions only lasted for the duration of the game being played. The game ended with a single "victor" or when conditions prevented further play-bad weather, darkness or a lost ball. The equipment consisted of only a ball, usually an old, discarded tennis ball with no rough, surface skin.

Despite the conditions that led to the demise of the original game, its resurrection in residential outdoor learning settings could restore benefits to childhood health and sociality through physical play activity. To do so in a modern society will probably require making the game more fashionable: involving new technologies and styling and indeed adding to the cost of preparing the child for the game. This, of course, is no different from any other modern versions of games and sports. In this particular sport, the aim, as with the original game, would be to reduce the overall number of players so as to arrive at a winner. In this way, children would learn about co-operation and competition. Such a game would develop some cognitive capacity as well as physical skills. Of course, it would be desired that the original game be resurrected in its original form and for it to be 
played and modified by children for children and for it to remain as much "child-directed play" as possible so that it is filled with enjoyment and friendship.

It is hoped that the transformation of this original game may encourage the re-design of other old games which would facilitate the re-enchantment of active play and games in outdoor settings with the overall intention of stimulating exercise and enjoyment in voluntary, child-directed play activities.

This brief example demonstrates how the context of self-directed physical activities might be incorporated into residential outdoor learning activities for the benefit of children's increased health and wellbeing through self-directed exploration and play.

\section{Acknowledgements}

The authors would like to acknowledge the contributions of staff from both Scottish Outdoor Education Centers (SOEC) and Duncan of Jordanstone College of Art and Design (DJCAD), University of Dundee, Dundee, Scotland for aspects of this study.

\section{REFERENCES}

Adler, P. A., \& Adler, P. (1998). Peer power. New York: Rutgers University Press.

Ames, M. (2007). Going postal: Rage, murder, and rebellion: From reagan's workplaces to Clinton's columbine and beyond. New York: Soft Skull Press.

Aspinall, A., \& Ujam, F. (1992). A projective approach to designing with children. Landscape Research, 17, 124-131. doi:10.1080/01426399208706375

Asthana, A., \& Revill, J. (2008). Is it time to let children play outdoors once more? The Observer.

Beard, C., \& Wilson, J. P. (2006). Experiential learning second edition: A best practice handbook for educators and trainers. London: Kogan Page Ltd.

Claxton, G. (2008). What's the point of school? Rediscovering the heart of education. Oxford: One World Publications.

Dansky, J. L. (1999). Play. In M. A Runco, \& S. R. Pritzken (Eds.), Encyclopaedia of creativity (pp. 393-408). London: Academic Press.

Eiser, J. (1986). Social psychology: Attitudes, cognition and social behaviour (2nd ed.). Cambridge, MA: Cambridge University Press.

Faculty of Public Health (FPH) (2010). Great outdoors: How our natural health service uses green space to promote well being. London: Faculty of Public Health.

Garvey, C. (1977). Play. Cambridge, MA: Harvard University Press.

Gazzard, A. (2007). Playing in a virtual world: Exploration and aspects of play. Proceedings of 17th International Conference on Artificial Reality and Telexistence, 288-289. doi:10.1109/ICAT.2007.27

Gill, T. (2007). No fear: Growing up in a risk averse society. Lisbon: Calouste Gulbenkian Foundation.

Gill, T. (2010). Nothing ventured. Balancing risk and benefits in the outdoors. Lifton: English Outdoor Council.

Gnanapragasam, A. (2010). Reorientating education towards sustainability: Promoting ecological literacy through outdoor learning in Scotland. Masters Thesis, St. Andrew's: University of St. Andrew's.

Haidt, J. (2006). The happiness hypothesis: Finding modern truth in ancient wisdom. New York: Basic Books.

Hattie, J. A., Neill, J. T., \& Richards, G. E. (1997). Adventure education and outward bound: Out-of-class experiences that make a lasting difference. Review of Educational Research, 67, 43-87.

Holloway, S. L., \& Valentine, G. (2000). Children's geographies, play- ing, living, learning. London: Routeledge.

Honoré, C. (2008). Under pressure: Rescuing our children from the culture of hyper-parenting. London: Orion Books.

Hughes, F. P. (1999). Children, play and development. Boston, MA: Allyn and Bacon.

James, A., Jenks, C., \& Prout, A. (1998). Theorizing childhood. Oxford: Blackwell Publishers Ltd.

Karsten, L., \& Vliet, W. V. (2006). Increasing children's freedom of movement: Introduction. Children, Youth and Environments, 16, 6973.

Kelly, G. (1955). The psychology of personal constructs. New York: Norton.

Learning and Teaching Scotland (LTS) (2007). Taking learning outdoors, partnerships for excellence. Glasgow: Learning and Teaching Scotland.

Learning and Teaching Scotland (LTS) (2010). Curriculum for excellence through Outdoor Learning. Glasgow: Learning and Teaching Scotland.

Lever, J. (1978). Sex differences in the complexity of children's play and games. American Sociological Review, 43, 471-483. doi: $10.2307 / 2094773$

Louv, R. (2005). Last child in the woods: Saving our children from nature-deficit disorder. London: Atlantic Books.

Maudsley, M. (2007). Children's play in natural environments. Children's Play Information Service: National Children's Bureau, UK.

Mayo, E., \& Nairn, A. (2009). Consumer kids: How big business is grooming our children for profit. London: Constable and Robinson Ltd.

Minister of Education (2004). Outdoor connections. London: Minister of Education.

Mittelstaedt, R., Sanker, L., \& Vanderveer, B. (1999). Impact of a week-long experiential education program on environmental attitude and awareness. Journal of Experiential Education, 22, 138-148.

O'brien, L., \& Murray, R. (2007). Forest school and its impacts on young children. Case studies in Britain Urban Forestry and Urban Greening, 6, 249-265.

Opie, I., \& Opie, P. (1969). Children's games in street and playground. Oxford, MA: Oxford University Press.

Petersen, A. F. (1988). Why children and young animals play: A new theory of play and its role in problem solving. Copenhagen: Munksgaard.

Piaget, J. (1962). Play, dreams, and imitation in childhood. New York: Norton.

Power, T. (2000). Play and exploration in children and animals. London: Lawrence Erlbaum Associates, Inc.

Quart, A. (2006). Hothouse kids: The dilemma of the gifted child. City of Westminster: Penguin Group.

Roussou, M. (2004). Learning by doing and learning through play: An exploration of interactivity in virtual environments for children. Computers in Entertainment, 2, 10. doi:10.1145/973801.973818

Schwartzman, H. B. (1983). Child-structured play. In F. E. Manning (Ed.), Association for the anthropological study of play (pp. 200214). New York: Leisure Press.

Schlumberger Excellence in Educational Development SEED (2004). A curriculum for excellence. Edinburgh: Schlumberger Excellence in Educational Development.

Sobel, D. (1993). Children's special places: Exploring the role of forts, dens, and bush houses in middle childhood. Zephyr Press, USA.

Sobel, D. (1996). Beyond ecophobia. Great Barrington: The Orion Society.

Ward-Thompson, C. (1995). School playground design: A projective approach with pupils and staff. Landscape Research, 20, 124-140. doi:10.1080/01426399508706466

West, J. (1996). Child centered play therapy. London: Arnold. 